\title{
Terroir and Cultural Identity
}

\author{
Brent A. Hammer
}

The purpose of this paper is to examine the relationship between terroir and cultural identity to illustrate that the concept is being employed as a means to reconnect people to the land or an ancestral heritage. The rapid pace of globalization has created a disconnect between identity and the land for many people. If it is true that $99 \%$ of human bistory has been spent as bunter-gathers, it is fair to say that we have a strong connection to the land as a sense of place in direct relation to food procurement. We know we can't go back to being bunter-gathers, but it doesn't mean we can't seek out or desire a connection to the land or an ancestral heritage. This connection can be represented by the concept of terroir. To synthesize the various definitions of terroir, it is important to explore the historical origins of the term. A philosophical view establishes that the concept of terroir exists as a separate experience to be reflected upon independent from the sensory experience produced by eating or drinking a food product. A selection of essays and articles are presented to illustrate that the buman or cultural component is the most important factor in considering the role of terroir in shaping or creating identity at ethnic, national, regional, and individual levels. Whether one simply believes the concept is being used as a marketing gimmick or that it resonates with our identities, terroir does exist in relating place, time and people to the production, consumption, and epistemology of our modern foodways.

T The War on Terroir, Reign of Terroir, In Defense of Terroir. No, this is not a military or political manifesto on some Western government's current paranoia with defending its nationhood or on its predilection to harass, torture or kill those that threaten their sense of democratic and capitalistic entitlement. It is not a typographical error. My computer does have spellchecker and it constantly reminded me with its little red squiggly line, "Are you sure you don't mean terror?" Yes, I assured my trusty computer as I ignored it for the twentieth time. My subject matter is of a much more lighthearted and pleasurable nature, that of food and identity. The authors of the above titles are merely employing a play on words (or expressions) to emphasize the silliness or irreverence to which they believe the subject matter of terroir deals with. Or are they? The purpose of this paper is to examine the relationship between the concept of terroir and cultural identity, and to demonstrate that this concept is being increasingly embraced as a means to reconnect people to the land or an ancestral heritage.

It is my intention to demonstrate that terroir is a serious issue and does exist in relating place, time and people to the production, con- sumption and epistemology of our modern foodways. I will present a synthesis of meanings to the word terroir to arrive at an operational definition, followed by a theoretical framework to approach the subject matter. A brief historical account of the origins of terroir will provide valuable context to understanding its meanings and various cultural examples will be used to illustrate these meanings.

\section{What Does Terroir Mean?}

Terroir, a French word, is derived from the Latin root terra, meaning 'earth'. One does not have to be a linguistic expert to understand that it is often very difficult to obtain literal translations between languages. The Concise Oxford Dictionary defines terroir as soil, ground, locality, place, or part of the country. Amy Trubek (2005), a chef, anthropologist and assistant professor of nutrition and food science at the University of Vermont, proposes that the word has many meanings even for the French and is often associated with a person's history with a particular place and described it as their roots. Elizabeth Barham (2003, 131), a rural sociologist, defines terroir as "a traditional French term referring to an area or terrain, usually rather small, whose soil 
and microclimate impart distinctive qualities to food products." Many people believe the word has its origins in viticulture (Heath and Meneley 2007) and that it refers to the relationship between quality, style and taste of the wine with its geographic origin (Van Leeuwen and Seguin 2006). Jerry Adler and Tara Weingarten (2005), writers for Newsweek magazine, suggest that terroir is the combined effect of all that you find in nature: topography, soil, subsoil and climate. Still others propose that terroir is not merely the soil, but includes the customs and ceremonies of the people who produced the food or drink (Scruton 2007a). In a different article on the same subject Roger Scruton (2007b), a philosopher, writer, and wine correspondent, simplifies his position by stating that terroir is the sense of a place, a time, and a culture. Trubek (2005) prefers the expression goût du terroir to suggest the meaning as the 'taste of place'. She continues to explain that, to the French, these words are more like "categories that frame perceptions and practices-a worldview, or....a foodview?" (Trubek 2005, 261).

It is best to stop or one can easily get carried away listing various definitions. What becomes evident is that terroir means more than a literal translation of a word or phrase. Terroir is best expressed as a concept, relating to food and foodways, that connects elements from the natural world with human intervention. If one chose to work with Trubek's suggestion one could expand upon it to look something like this: "taste" includes more than the physiological or sensory sensation of eating or drinking a food product. It would encompass all the human senses as well as the full cognitive and cultural realm elicited by the food product to the extent one is capable of experiencing it. "Place" includes all the physical elements of geography, with the scientific elements of geology, climate and weather. But most importantly place includes the people, the customs and traditions and their ancestral heritage within a physical and temporal space. The simple word "of" is the connector between the two that acknowledges the relationship between taste and place. Terroir, as Adler and Weingarten (2005) succinctly suggest, is best expressed by metaphor and not by scientific analysis. Therefore, within this metaphoric context I will use Trubek's (2005, 260) simple but inclusive "taste of place" as my operational definition of terroir.

\section{Theoretical Perspectives}

Research and writing on terroir cover a wide range, from a purely positivist approach of scientific proof of its existence (Van Leeuwen and Seguin 2006), to functionalism (Feagan 2007), to a philosophical discourse on epistemology (Scruton 2007a), to historical particularism (Whalen 2007), and to popular musings by oenolophiles and literary scribes (Adler and Weingarten 2005). As a subject matter it touches on politics (Josling 2006), economics (Heath and Meneley 2007), history (Helstosky 2003), and religion and spirituality (Trubek 2005) within both local and global contexts.

The common threads in all this literature are food, people, places and the relationships between them. The dates, range of titles and variety of publications in my reference materials suggest terroir is currently topical and somewhat controversial as an academic and dinner table subject. Holistic, dynamic and relativist concepts are all important ingredients in conducting research into the concept of terroir.

However, in dealing with a concept such as terroir it is helpful to tenuously construct a theoretical framework based on some of the key components. Taste, as briefly discussed above in the context of my operational definition, represents much more than the chemical senses of salty, sweet, bitter, and sour identified by the biological receptors on the tongue (Bartoshuk and Duffy 2005). E.N. Anderson (2005), a professor of anthropology in food studies, emphasizes that it is the relationship between the physiological and the cultural that allows us to create taste. Culture then becomes the magical ingredient that brings terroir to life. We are not, after all, interested in actually consuming dirt or rocks to discern geological and chemical elements like sandstone or alkaline (Van Leeuwen and Seguin 2006). What we are interested in when we produce, sell or consume a food product is what it or the process represents or means to the people involved and affected by it. 
It has long been known in anthropological studies that food consumption and food practices have deeper meanings than just providing nutrients to the body. Research by Mary Douglas (1966) and Claude Levi-Strauss $(1969,1962)$, pioneers in the study of foodways, has demonstrated the connection between food, cultural meanings, cultural differences and identity. Levi-Strauss theorized that the cooking process changed nature into culture. Douglas saw the act of performing food preparation as a material and social transformation involving the knowledge and skills of the people. Brillat-Savarin, in his 1925 publication The Physiology of Taste, produced the frequently quoted line "tell me what you eat and I'll tell you who you are" (Heath and Meneley 2007, 599) to reflect the powerful connection between food and identity. Terroir, in its relation to the origin, production, distribution and consumption of food, by extension becomes capable of invoking and reflecting cultural identity.

The link between place, space and identity also provides a theoretical understanding towards the concept of terroir. The rise of the post-industrial modern era saw the rise of the nation state as the primary unifying identity for individuals of regional, ethnic, and cultural differences (Feagan 2007). Like other anthropological concepts considered traditional, the sense of place was now believed to represent old fashioned, irrelevant, static, and frozen in time. The process of globalization was seen as creating a world of increasing "placelessness" (Feagan 2007, 38) where the significance of place in people's lives was reduced or considered to be of negligible relevance. It was thought that people would become cosmopolitan citizens of this new global and universal world order.

The work of prominent human geographers J.A. Agnew and J.S. Duncan (1989) revitalized the importance of place as a concept in the social sciences. They redefined place as the structuring or mediating context for social relations and suggested that place, as a spatial concept, could not exist without people having a strong identity connection to a geographic location. To the contrary, geographers and other social scientists had began to notice that people were not let- ting go of the their community or regional place and the identities that they associated with that place. In fact this reemergence of place as an expression of identity seems to represent a growing awareness and resistance to the deterritorialization brought on by global change (Feagan 2007). This conscious effort to (re)create distinctive or sovereign qualities as identities markers attached to a place is rooted in what I refer to as a spiritual connection to the land or an ancestral heritage.

Scruton (2007a) sees the concept of terroir as a celebration of our relationship with our natural surroundings. Terroir reflects the history, customs, and ceremonies of people, not merely the soil of a place. The author considers wine as a living thing with terroir facilitating the transformation of the grape into wine, followed by the transformation of the soul when we drink the wine. Scruton suggests this represents the transition from hunter-gathers to farmers to modern civilization where settled people now belong to a place_-a place with a memory.

Scruton distinguishes between sensory pleasure and aesthetic pleasure, which he says is dependent on your learned knowledge or culture. He describes taste and smell as secondary objects that form associations with their primary objects, such as food or a beverage. That then creates an experience unto itself with the ability to link people, place and processes back to the primary object. It is this experience, that now has a life of its own, that humans can reflect upon. Therefore, terroir is not necessarily inherent in the primary object, say wine or food, but a possible association that may be linked to it depending on the cultural relevance to the individual experiencing the association.

Scruton states that in experiencing terroir people are able to know the history, geography, and customs of a community. This epistemological perspective, despite the potential philosophical pitfalls or seemingly circular logic, is I believe essential for establishing the concept of terroir as a reflexive experience that can be appreciated by itself, not as an existential one but rather as a shared cultural experience. To this extent terroir can be viewed as an analytical construct within a cultural domain. 


\section{The Origins and History of Terroir}

Terroir as a concept, as I have defined it, is arguably less than 100 years old. Yet the roots of its origin could be conceived as being somewhat primordial. As stated by noted winemaker and geologist David Jones, "What you're tasting in a bottle of wine is a hundred million years of geologic history" (Gee 2004, 119). Many perspectives on the origin of life agree on the order of appearance: the earth or land came first, followed by the flora and fauna, and the people came last (Ives 2007).

It is commonly accepted in anthropology that the majority of human existence has been spent as hunter-gatherers (Moran 2007), successfully roaming and living off the land. Therefore, it is easy to believe why humans would have such a deep spiritual connection to the land and what it provides for them. This forms an underlying cosmological basis for the concept of terroir. However, what is relevant to the understanding of my research problem is the socio-cultural realm of our contemporary Western society.

Philip Whalen (2007), a folklore scholar, notes how the use of geographical determinism to explain social and political practices is a tradition in France that goes back at least 500 years. Regional identity became part of a strategy of class struggle between the elite and peasants, and between urban and rural people. The concept of terroir began to be used extensively in France in the 17 th century. This use of geographical determinism led to a theory of historical development focusing on the dynamics between people and their environment and was not always used in a complimentary way (McGee and Patterson 2007).

The meaning of terroir began to shift in the early 19th century when a wealthy Burgundian landowner noticed that although all the wineries essentially made wine the same way, some tasted better than others (McGee and Patterson 2007). From this observation he surmised that the differences must be due to the terroir, specifically the soil and rocks under the vineyard. Then Vidal's Principles of Human Geography, published in 1921, proscribed an interrelationship between earth and man. This relationship was based on physical laws and ecological understanding that emphasized the interactions between society and its terroir and gave rise to a "scientific credibility and therefore greater utility to the French discourse of terroir" (Whalen 2007, 24).

Trubek (2005) suggests this interrelationship led the French to develop what they believed was a national foodview. They believed that the physical environment, the soil, roots, etc. of a place created distinct tastes in wine and food. This fundamentalist view of terroir was seen as reflecting reality for the French. Trubek argues that a close examination of historical events reveals a slightly different and more accurate picture. Increased urbanization and industrialization led to the emergence of a new connection between agricultural practices, rural life, food and drink. Regional cuisine emerged from distinct geographic regions, where taste and quality of flavor are not only linked to location but to production style and the producers themselves. The Michelin tire company began their publication of food and travel guides to promote these regional cuisines with the purpose of increasing travel and selling more tires. The promotion of rural tourism also included the development of regional gastronomy and the phrase "celebrating the taste of place." What has transformed, as Trubek outlines, is the notion that it is the cultural component, the people and their history, which ultimately defines the concept of terroir.

Whalen (2007) supports this view in his article "'A Merciless Source of Happy Memories': Gaston Roupnel and the Folklore of Burgundian Terroir". Here the author examines how folklore and the concept of terroir were used to promote Burgundian regional culture between the two world wars (1919-1939). Gaston Roupnel was a provincial folklorist who exploited the images of rural life to create a shift in French cultural identity. The goal was to combine conservative cultural traditions with modern industrial practices to stimulate growth in the economy while fostering pride in rural France.

Roupnel promoted rustic stereotypes, through folkloric gastronomical fairs and wine festivals, to reinvent a traditional, regional cultur- 
al identity as an alternative to the cosmopolitan French Nationalist identity that was growing at the time. Carcano notes that Roupnel depicted a "timeless peasant civilization, representing the repository of tradition... retaining the traces on France's Celtic origins... and animated by costumed feasts, chants, and convivial dance (Whalen 2007, 25). Roupnel asserted that the concept of terroir contained the spirit of the past, transcending time and all of human life.

Whalen reports that Roupnel's interests then shifted to the vignerons (grower vintners) of the Burgundian region. This slight change in direction was meant to shift the French rural identity from the paysan (peasant farmer) to the vigneron, a more iconic figure, by invoking the concept of terroir to specifically viticultural practices. Roupnel wrote in 1936 "Our Burgundian wines are as much the children of human hands as that of the soil" (Whalen 2007, 30). Whalen concludes that it was Roupnel, and regional intellectuals like him, who created the current version of the concept of terroir that instilled a regional folk identity into the national consciousness and that continues to shape contemporary notions of French identity today. To that I might add the creation of a very successful marketing campaign, as well.

This combination of terroir, identity, and marketing is brought up to date by Kolleen Guy's (2004) article "Wine, Ethnography, and French History". Guy, an associate professor of history, highlights the reverence and passion with which the French still maintain for goût du terroir. The author illustrates how the case of Jose Bove, a successful sheep farmer who attacked a McDonald's restaurant in France, facilitated the emergence of terroir and especially wine as an "ideal political tool endowed with enormous symbolic power" (Guy 2004, 164). Bove's headline-producing actions were seen as both promoting the ideology of terroir and attacking the homogenization of food by American political ideology and multinational corporations. The words terroiristes and terroirism (Scruton 2007a) are terms employed to reflect the intensity of anger and the passion of national pride involved in the issue of terroir.

Guy (2004) notes that these issues of international gastro-politics have been stirring for over a hundred years. The author proposes that to understand these recent conflicts it is useful to examine links from the past to the present with regard to small-scale wine producers. To support this view, the author reviews two books, one by Winnie Lum and the other by Robert C. Ulin, who conducted ethnographic fieldwork in the south of France in the late 1980s and early 1990s. These books provide some historical background into the concept of terroir and the construction of regional identities where one discovers that passion was not always ideal or celebratory.

Guy suggests both books depict the world of ordinary wine producers whose passion sometimes turns into rage, similar to the angry protest by Bove. The French have laws protecting products of terroir, like wine, called appellations d'origine contrôlées (Barnum 2003). These products are patriotically treated as national brands, much like corporations protect trademarks, because they are believed to represent quality and an authentic experience of goût $d u$ terroir, and by extension French cultural identity. Guy is critical of both authors for overemphasizing the economics of labor organization and protest in shaping the regional identities, but then commends them for suggesting that wine is an invented tradition invested with "cultural capital" grounded in the notions of terroir. Guy concludes by acknowledging that products of terroir are increasingly becoming more popular and diverse around the world. This is creating a corresponding rise in the number of controls and agencies to protect producers and inform consumers about the issues relating to the concept of terroir (Guy 2004). It is to this discussion that I now turn.

\section{Global Terroir}

I believe Tim Josling's (2006) use of the expression "the war on terroir" is his article titled "The War on Terroir: Geographical Indications as a Transatlantic Trade Conflict" is not meant to be irreverent or to poke fun at oenophiles (wine lovers) as I initially suggested. Josling is a professor emeritus of the Food Research Institute at Stanford University. His article, presented as a presidential address, highlights the political seriousness and global implications for the use of 
the concept of terroir. The author describes the concept of terroir as an essential link between location of production and a specific quality attribute. His article explores the legal and economic arguments in trade negotiations and disputes concerning agricultural and food products between the United States and the European Union (EU). The author suggests that there is a growing interest in the protection of cultural goods and those goods that embody traditional production methods, such as the concept of terroir.

Josling incorporates the concept of terroir with the term geographical indications (GIs) to represent a form of intellectual protection to be used in the examination of the information about consumer attributes of a food product. GIs, Josling states, indicate that place names reflect a certain quality, taste, cultural identity, and other related information important to the consumer. The author addresses the important question of whether GIs protect cultural traditions and practices or are simply being used to provide marketing advantages. He emphasizes that this is an area of disagreement and conflict between the EU, which has extensive systems and protective regulations of GIs, and the U.S., which does not.

I believe this article is important because it draws attention to the growing interest and regulation in the protection of cultural goods and to those goods that embody traditional production methods. The author acknowledges that in this New World of global markets and multilateral food regulations there is little to be gained by impeding the natural spread of food cultures (Josling 2006). He does agree that the mystique of terroir may be beneficial in the development of agri-tourism. But to some the "war on terroir", however it is employed, is also a war on cultural identity. Although cultural identity is not a focus of this article, I see it as inherent in the Old World-New World relationship of contrasting values suggested by the terms colonial, conflict, transatlantic, dispute, and war.

Feagan (2007) goes a bit further is his discourse about the relationship between local and global food systems. The author discusses how the concept of terroir and labels of origin are valuable for connecting food to a place and how they relate to the local food systems (LFS) movement. He recognizes terroir as a socio-cultural construct that addresses the relationships between nature, quality, region, producers, and consumers. Feagan $(2006,25)$ suggests that LFS can act to reconnect "power and knowledge relationships in food supply systems that have become distorted by increasing distance (physical, social and metaphorical) between producers and consumers." The author continues to state that LFS, employing the concept of terroir, can shorten the food chain to bring consumers closer to the origins of their food, to in essence reconnect them to the land or an ancestral heritage.

Farmers' markets and community gardens are seen as one way that direct contact brings food producers and consumers closer both geographically and socially (Feagan 2006). The quality and cultural identity embedded in the farming practices and traditional customs of production, as the concept of terroir, are seen as fundamental information important for both the producers and the consumers. It is then believed that this information enables consumers to place value judgements of quality and authenticity on products they associate with a region, country, method of production, or on their terroir.

Feagan also recognizes terroir as a sociocultural construct that addresses the relationship between nature, quality, region, producers and consumers. The article acknowledges that the concept of terroir is being used globally by many countries and regions and has broadened the food spectrum to a vast array of products. The author suggests that in this day of increased mobility and globalization people are trying to recapture a spatial-cultural identity and that the concept of terroir is a useful and powerful means to do that (Feagan 2006). An exploration of some specific examples will further demonstrate how the concept of terroir is being employed as a means to reconnect people to the land or an ancestral heritage.

\section{Terroir of California Wine}

What better place to begin a cultural journey back to the land and the past than the land of sun, surf, paparazzi and Paris Hilton? Whether 
one believes California is a cultural wasteland doomed to someday fall gracelessly into the $\mathrm{Pa}$ cific Ocean or the cultural bastion to which the entire world aspires, there is little argument that it is the land of a thriving and successful local and global wine industry. It is also the place where the concept of terroir has been vigorously studied, practiced and debated to the point that it has become part of the local mantra for many Californians. Controversy concerning terroir in wine was elevated to the international stage when Napa Valley Cabernet Sauvignons were rated higher than prized First Growth Bordeaux from France in a blind taste test conducted by a panel of international wine experts in Paris (Scruton 2007a).

California is also the place where the nature-culture duality of terroir is intensely debated. Scientific studies, such as that of Van Leeuwen and Seguin (2006) attempt to understand terroir as it specifically relates to viticulture are a regular academic pursuit. Terroir is approached as an interactive ecosystem where climate, soil, and vine are interpreted by how they relate to quality, taste, and style. Natural environmental factors are broken down into macro, meso, topo, and microclimates. Soil, geology, pedology, agronomic, and water uptake conditions are all analyzed in relation to their possible sensory attributes of wine. Howell and Swinchatt (Anderson 2005) note a vineyard in northern California that produces three different wines from three different soil types believing that each one tastes different. While concluding that the natural environment does have a scientific basis for influencing the wine, Van Leeuwen and Seguin (2006) concede the difficulty in studying terroir because of the many variables involved, the least of which is the human element, in this interactive ecosystem.

Robert McGee and Daniel Patterson, two New York writers, poke fun at California wine experts who claim to be able to taste the earthiness and "minerality" in a wine by asking the question, "Does terroir really exist?" (McGee and Patterson 2007,2$)$. They acknowledge the concept has appeal to connect nature and place to people in a delocalized world but suggest it is a little more complicated than tasting the earth. They wonder how winemakers get the flavor of dirt and rocks into the glass, especially since wine is made by fruit grown on a vine above the ground. They elaborate by noting that essential minerals in the rock, such as sodium, potassium, calcium, magnesium, and iron, are dissolved by the soil moisture and mainly affect plant growth. The earthy and mineral aromas and flavors actually derive from the interaction between the grape and yeast during production. It is these transformations created by metabolizing yeast, a process strongly influenced by the winegrower, which contribute to the taste of the wine.

Therefore, they believe it is the grower who controls and manipulates plant growth, and the winemaker, who makes hundreds of choices in the transformation process, that ultimately determines the final product. They suggest that the concept of terroir has been one of the longest running and most successful marketing campaigns of the modern era, pitting Old World tradition against New World bravado. But then they ask why, if terroir is mostly about marketing and economics, have so many Californians and indeed most Americans, "embraced the concept with near-religious zeal" (McGee and Patterson 2007, 4).

The authors answer by exploring the complex relationship between tradition, culture and taste. They cite pioneering French oenologist Emile Peynaud (McGee and Patterson 2007, 5) who wrote about the "dual communion" represented by wine and the role of human intervention with nature. The authors conclude by suggesting wines taste the way they do because people chose to make them taste that way, and that wines are an expression of culture, not nature.

This embracing of the concept of terroir by American wine enthusiasts may be seen as a way to reinforce the traditional and spiritual role of wine in human life to connect people to the land and to one another. Terroir is the mediator between nature and culture (Trubek 2005). Evidence of the tremendous growth in small boutique, organic and hobby wineries in California 
would support this notion (Gee 2004). Wine producers have changed their original labeling practices from focusing on the varietal or style of grape to emphasize the place name of the winery, which is often a family name, and the vintage year (Adler and Weingarten 2005). Of course many of the original wineries in California have Old World connections through either transplanted vines or families or both. Many California labels are now also highlighting the specific vineyard the grapes are from, along with notes on the back of the bottle to reflect the specific terroir of the wine. This terroir may refer to place, people, tradition, methods, and the consumer's potential experiences from drinking the wine. Is this a reflection of family tradition and ancestral heritage or an act of shameless self-promotion? The fact that these may be either old or new elements simply reiterates the notion that cultures are dynamic and not static. Regardless, there is this strong desire to connect the new with the old, with culture to nature. Deroy (2007) expressed this notion by suggesting that wine gives people the feeling that they are participating in a deeply rooted culture. This Californian understanding of the concept of terroir seems ideally illustrated in this quote from the movie Sideways (Payne and Taylor 2004) where Maya, the protagonist's love interest, describes what wine makes her think about:

I do like to think about the life of wine, how it's a living thing. I like to think of what was going on the year the grapes were growing, how the sun was shining that summer or if it rained... what the weather was like. I think about all those people who tended and picked the grapes, and if it's an old wine, how many of them must be dead now. I love how wine continues to evolve, how every time I open a bottle it's going to be different than if I had opened it on any other day. Because a bottle of wine is actually alive-it's constantly evolving and gaining complexity. That is until it peaks - like your '61 - and begins its steady, inevitable decline. And it tastes so fucking good [Payne and Taylor 2004].

\section{Terroir of Vermont Maple}

Black (2006) reports, with an appropriate sense of humor, on a project coordinated by Amy Trubek. The goal of this project was to apply techniques of the wine world to determine if a maple syrup terroir exists. Scientific equipment and procedures were used to analyze the chemical properties of different syrups to establish characteristics that may account for different tastes. The theory of the project was to suggest that if different maple trees on different soil types produced different syrup flavors, producers could use that information to promote Vermont and regional syrups over other brands from different places.

The use of words like "mineral" and "flinty" on the label could invoke the concept of terroir, in a state that claims to prize its rural heritage, as a means of reinforcing their cultural identity: "We are different and so is our syrup" (Black 2006, 11). Trubek argues that the terroir of maple syrup matters because the small, local syrup makers are competing with the corporate food giants. Terroir as a marker of identity and used for marketing is essential to the Vermont producers.

The results of the tests did conclude that maple trees from different geologic conditions produce different quantities of chemical elements that could affect the taste of the syrup. The researchers also attempted to address production methods and other intangible factors, but due to the informal nature of the study, lack of funding, and ability to consume only so much maple syrup at a time, they were unable to continue their project. However, the article does demonstrate that the concept of terroir is presently applied to different food products in an attempt to reinforce regional and cultural identities and market local commodities.

\section{Terroir and the Feta Wars}

The production of feta cheese in Greece can be traced back 6000 years (Economou 2003). Feta cheese has had strong links with Greek history and literature since ancient times. Most of the feta produced in Greece in consumed domes- 
tically, illustrating how important it is to traditional Greek food, customs, and identity. In 1994, Greece applied to the European Union (EU) to have feta cheese recognized as a Greek branded product under the Protected Designation of Origin (PDO) status. The PDO was created to assure the quality of traditional food products.

The Greeks believe that feta cheese is symbolic of their country and their cultural identity. Denmark, Germany, and France, countries that also produce feta, disagree and have fought against the designation. They see feta as a generic term not symbolic of Greek origin. Yet Denmark only began making feta cheese in 1963 and Germany in 1985. It is not difficult to see Greece's position, 6000 years compared to 20 or 45; there is a slight difference here.

However, Greece's position is also based on quality of the product and control of production methods to establish a terroir. Greek feta is made from sheep or goat milk, not cow milk like other countries use. Traditional feta is not brined in salt; it is sprinkled with coarse salt and flipped for up to 24 hours to allow subtle herbal undertones to evolve (Kochilas 2006). Large triangular wedges are placed in old birchwood barrels, salted again, and aged for a legal minimum of two months and up to six months for high grade feta. Greeks believe their production methods are unique, including the dry climatic conditions that produce the feed for the sheep and goats' subsistence (Economou 2003).

This is a useful example of the global terroir wars that Josling articulated where nations are trying to protect and preserve their cultural identity by promoting the origin or connectedness of a certain product to their land or traditional methods and heritage. This case deals with legal repercussions and intellectual property matters concerning the World Trade Organization and is an issue of global economic concern. More importantly, I believe it represents the power of terroir as supported by an EU market survey that indicated $79 \%$ of EU consumers believed that feta evoked a place of origin and not a type of product. When they thought of feta they regarded it as Greek and felt they were guaranteed a quality product (Economou 2003). Kochilas (2006) sug- gests that in many parts of the country feta is so strongly associated with their identity and terroir that the Greeks simply refer to it as cheese.

\section{ITALIAN TERROIR}

Historian Paolo Sorcinelli suggested that when studying the history of Italian food it is best to think of it as the history of appetite and hunger rather than the food itself (Helstosky 2003). He believed that the meagre food habits were the product of a meagre physical and sociopolitical environment. To this end Carol Helstosky, also a historian, examines and compares two cookbooks to explore the history between Italian foodways, in particular the preparation and consumption of food and Italian cultural identity.

Helstosky (2003) suggests that the cookbook by Artusi attempted to bring Italians together through a shared language and practice about food preparation and consumption based on local and national products that were rooted in traditional customs. It was intended that despite regional and class differences throughout the country, this would enable the cookbook's readers to think of Italy as a nation with similar cuisine and food practices. Historical events envelop a heritage component to invoke the concept of terroir. In a country with a history of political and economic turmoil and limited agricultural land, the food habits of the late 19th and early 20 th centuries were considered to be the results of this unstable and unhealthy environment where even the wine was bad.

In an attempt to change these bad habits, Artusi encouraged the readers of his cookbook to call on their sense of Italian heritage. He wanted then to think about the purchase, preparation and consumption of certain foods in terms of what is best for the national identity and their individual identities. His vision was based on three principles: hygiene and health, the construction of middle class custom, and the nation's regional diversity of produce and cooking styles. By educating the middle class Artusi hoped these new foodways would become distinct and desirable (Helstosky 2003). This would form the essence of the concept of terroir that he then hoped 
would contribute to a national cuisine and unite the nation.

The other cookbook, by Marinetti, took a more positivist or practical approach to the task of improving Italian foodways. He promoted the abolishment of all traditions and customs and placed food production and distribution in the hands of the state in order to create an entirely new food system. Fascist policies and propagan$\mathrm{da}$ of the time were reflected in his cookbook and were meant to counter the more naturalist efforts of Artusi's earlier publication. Helstosky notes that while Marinetti and his cookbook quickly faded and were forgotten, Artusi became loved and revered with his cookbooks still available today; he is "still considered the indisputable father of traditional Italian cuisine" (Helstosky 2003, 134). Today, these results appear to be represented by a cuisine that emphasizes the concept of terroir, embodied in a passion for their national, regional, and individual heritage as a vital component of their cultural identity; and yes, the wine has improved.

\section{TERroir AS ARTISANSHIP}

Heath and Meneley (2007) discuss the ways in which techne, as craft or artisanship, and technoscience are used to mediate the production and consumption of food. The authors, referencing Marx's theory about the severance of the relationship between production and consumption, examine how specialty commodities, such as foie gras, cheese and olive oil, are being used to reinforce cultural identities by invoking claims of terroir. Terroir is defined here more from the position of the process of food production rather than the soil or climatic conditions or contributions. This terroir, infused with traditional methods and customs, is used to create and promote products designed to reflect the regional or ethnic identities of the producers or distributors to consumers.

This article highlights how the human intervention component, as craft or artisanship, can employ the concept of terroir as a powerful communicator of national, regional, ethnic, and cultural identity. The authors reference the organic, farm to table, and slow food movements as examples of this strategy. These artisans emphasize the use of locally sourced ingredients, traditional methods, and standards of quality to combat the homogenization and industrialization of global food producers. One example is from a small-scale New England cheese maker who aims to recreate the "natural-technical traditions of their European predecessors" (Heath and Meneley 2007, 596) through what might be called reverse-engineering terroir strategy. Another example, from a traditional Camembert cheese maker, proclaims the fight is to preserve the smell of the farm, grass, and the cows in his cheese.

The authors are astute in pointing out that this relationship between artisanship and terroir may create somewhat of a paradox. In attempting to decommodify food products by promoting the concept of terroir, these artisans may end up actually increasing the value of the food product purely as a commodity (Heath and Meneley 2007). This may be evident by the persuasive marketing strategies of fast food restaurants that employ what might be called psuedo-terroir and brings up the issue of "authenticity" and what constitutes "traditional".

\section{ANALYSIS}

Questions of authenticity and of what constitutes traditional, in regards to food and foodways, and their relationship to cultural identity are relevant to the concept of terroir to the degree that they are also examined as cultural constructs. James (2005) asks if food and foodways can still act as strong markers of cultural identity in a global food system and whether the increased homogeneity of cuisine blurs our sense of cultural distinctiveness. She suggests the cosmopolitan juxtapositions and blending of foods can create conflicts in cultural identity, including that of the individual consumer. Just think of "all you can eat buffets". However, James states that foodways should be seen as flexible markers of cultural identity and acknowledges that there is a constant intra and interrelationship between food, foodways, and culture. She even suggests that the consumption of "foreign food" is a way for people to validate 
their own sense of local and cultural identity.

Goody (1982) also addressed these issues concerning the validation of the role of food and foodways with respect to cultural identity. He gave the example of pizza and pasta being accepted as traditional cuisine representative of all of Italy, yet historically they were only a small regional phenomena. Maize, another example, is regarded as a traditional staple food of Africa but originated in the Americas. Goody emphasized that authenticity needs to be viewed as a reflexive concept that recognizes the importance of a holistic, dynamic, and timeless approach to the understanding of culture and cultural constructs. This is where I believe the concept of terroir plays a pivotal role in connecting these different elements. As Trubek $(2005,268)$ suggested, terroir "reflects reality" in the sense of what is culturally relevant to you at a given place and time. Traditional foodways are not meant to represent something old fashioned, irrelevant, static or frozen in time but should be seen as a way of representing or "preserving the historical qualities of local flavors" (Trubek 2005, 268).

The case of Italian terroir I discussed is an excellent example of the cultural relevance of the use of terroir as a concept to unite a nation and build a new sense of cultural identity through the process of reauthenticating and reinterpreting the notion of traditional. The example of California wine terroir illustrates people and regions attempting to create a new cultural identity, that despite contemporary modifications, is still rooted in a traditional or ancestral identity. Many of the other articles demonstrate the global influences of our cosmopolitan world by legitimizing terroir through local, regional, national and international laws and government regulations. The case of Greek feta cheese obtaining EU designation is a clear example of this. Transnationalism, cosmopolitanism, and globalization are all realities in the current cultural milieu, yet despite the projected homogenization of food and foodways they have not produced a comparable homogenization of cultural identities (James 2005). In fact, it would appear people are more aware of the potential disconnect to their cultural identity and work harder to reconnect to a place, to the land, or an ancestral heritage. I agree with Trubek's (2005) suggestion that terroir has been increasingly used to promote nostalgia over the past thirty years. But I would further suggest that it is a nostalgia with an essence of a rooted past. The proliferation of its use in the menus of many of today's "fashionable" or "trendy" restaurants would certainly support this notion. This also reinforces the importance of recognizing and acknowledging that the concept of terroir is a construct reflecting nature and natural processes that we use to define our perceived cultural reality.

\section{Conclusion}

When you drink a bottle of Zinfandel wine from California, are you experiencing terroir? What if you knew the vintner was the Turley wine company? What if you knew it was from their Paso Robles winery in the southern region of the Salinas Valley? What if you were told this was a very good region for growing grapes due to the geologic and climatic conditions? What if you knew it was specifically from their Pesenti vineyard? What if you knew the vines were 85 years old? What if you knew the vines were from original clippings brought over from Italy by the Pesenti family? What if you knew the vintage of the bottle was 2003? What if you were told that was an exceptional year for the grapes due to near perfect weather conditions? What if you drank that wine while standing in that very winery in the rolling hills of Paso Robles just east of the beautiful Pacific coast under the glorious California sunshine? And would the sensory, cognitive, and cultural experiences be heightened because you were there and in the moment?

Yes, they certainly were for me, despite the fact that it was actually raining that day. Did I experience the concept of terroir as the taste of a place? I believe I did even though I had never tasted the wine before. In fact, I had never even heard of Turley wines before, let alone the Pesenti vineyard. Nor had I ever been to Paso Robles or heard of it until we researched for a trip to California. Will I experience the concept 
of terroir when I open or even look at the bottle that I brought home from that same vacation? Looking at the bottle certainly invokes the memories I have from that trip. But it also invokes the information and knowledge that I learned from that specific experience. It represents the experience of a temporal, spatial, and cultural place. Would I have the same experience if I knew none of that information and had just gone to the local wine store and bought that bottle? Definitely not; as Crane (2007) points out, the wine may speak of terroir but not in a literal sense, as the wine itself has no message. So it will not matter as much what it physically tastes like when I actually take a sip as what and who it represents or what it makes me think about, as the previous quote from the movie Sideways (Payne and Taylor 2004) illustrated.

What is apparent to me from my research on this paper and from the examples reported is the underlying, powerful influence of the human component to the concept of terroir. The potential for human intervention or modification exists in the growth, production, distribution, and consumption phases of a food product, therefore imparting a sense of cultural identity to it. As mentioned earlier, we are not really interested in eating dirt or tasting minerals in our foods, but rather in what the experience represents or means to us on a sensory, emotional, cognitive, and therefore cultural level.

So does the concept of terroir exist for the individual who does not have the learned or shared experiences of relevant cultural knowledge? Are they incapable of experiencing terroir if they are unaware of it? There are many articles discussing the philosophical nature of science, aesthetics, objectivity, and subjectivity in relation to the concept of terroir. An underlying component evident in my research is the essence of a spirituality that exists between the concept of terroir and cultural identity. There seems to be a primordial instinct that as humans we have a need and desire to connect or reconnect to the land and our ancestral heritage. It only makes sense that in a busy world of increasing homogenization of products and technology, people would attempt to reinforce their cultural and individual identities to avoid being swallowed up by a cosmopolitan worldview where deterritorialization blurs our sense of who we are.

The concept of terroir is a perfect cultural construct to relate place, time, customs, and traditions to the production, consumption, and epistemology of our modern foodways. It is a way to express social cohesion, display a sense of patriotism or pride, and to embrace our cultural identity. Terroir is a way to ground us to a place, to the land, and to an ancestral heritage. Advances in biological and evolutionary psychological research may one day reveal that the human brain is in fact hardwired for terroir. While I do not believe that it would imply that we are all of French descent, it would suggest that we are all biologically capable of experiencing the taste of a place whether we know it or not. We just require the sociocultural milieu to express and more importantly to share it in. The concept of terroir is intricately intertwined with our sense of community and place, and is a powerful communicator of this relationship between food, foodways, and our cultural identity.

\section{ACKNOWLEDGEMENTS}

I would like to thank Dr. Helen Vallianatos, my graduate program advisor, for her guidance and support on this paper, and all past, present, and future projects. I would also like to thank the anonymous reviewers of this paper. This paper was prepared for ANTHR 471: Independent Research.

\section{ReFERENCES Cited}

Adler, Jerry, and Tara Weingarten. 2005. "The Taste of the Earth." Newsweek 145 (9): 54.

Agnew, John A., And James S. Duncan (eds.). 1989. The Power of Place: Bringing Together Geographical and Sociological Imaginations. Boston: Unwin Hyman.

Anderson, Eugene N. 2005. Everybody Eats. New York: New York University Press.

Barnum, Elizabeth. 2003. "Translating Terroir:

The Global Challenge of French AOC Labeling." Journal of Rural Studies 19: 127-138.

Bartoshuk, Linda M., and Valerie B. Duffy. 
2005. "Chemical Senses: Taste and Smell." In The Taste Culture Reader, edited by Carolyn Korsmeyer, pp. 25-33. New York: Berg.

Black, Jane. 2005. "Fresh from Vermont's Maples, a Taste of Terroir.” New York Times, December 20: F11.

Crane, Tim. 2007. "Wine as an Aesthetic Object." In Questions of Taste: The Philosophy of Wine, edited by Barry C. Smith, pp. 141-156. New York: Oxford University Press.

Deroy, Ophelia. 2007. "The Power of Tastes: Reconciling Science and Subjectivity." In Questions of Taste: The Philosophy of Wine, edited by Barry C. Smith, pp. 99-126. New York: Oxford University Press.

Douglas, Mary. 1966. Purity and Danger: An Analysis of the Concepts of Pollution and Taboo. London: Routledge.

Economou, Georgia. 2003. "Feta 2: The Feta Cheese Wars.” Electronic document, http:// www.amercian.edu/TED/feta2.htm, accessed March 26, 2008.

Feagan, Robert. 2007. "The Place of Food: Mapping Out the 'Local' in Local Food Systems." Progress in Human Geography 31 (1): 2342.

Gee, Henry. 2003. Review of The Wine Maker's Dance: Exploring Terroir in the Napa Valley. Berkley: University of California Press.

Goody, Jack. 1982. Cooking, Cuisine and Class. Cambridge: Cambridge University Press.

Guy, Kolleen M. 2004. "Wine, Ethnography, and French History." Culture \& Agriculture 26 (1\&2): 164-168.

Heath, Deborah, and Anne Meneley. 2005. "Techne, Technoscience, and the Circulation of Commestible Commodities: An Introduction." American Anthropologist 109 (4): 593-602.

Helstosky, Carol. 2003. "Recipe for the Nation:

Reading Italian History Through Scienza in Cucina and La Cucina Futrista." Food \& Foodways 11: 113-140.

Ives, John W. 2007. "13,001 Years Ago-Human Beginnings in Alberta." In Alberta FormedAlberta Transformed, volume 1, edited by Michael Payne, Donald Wetherill and Catherine Cavanaugh, pp. 1-36. Edmonton: University of Alberta Press.
James, Allison. 2004. "Identity and the Global Stew." In The Taste Culture Reader, edited by Carolyn Korsmeyer, pp. 372-384. New York: Berg.

JosLing, Tim. 2006. "The War on Terroir: Geographical Indications as a Transatlantic Trade Conflict." Journal of Agricultural Economics 57 (3): 337-363.

Kochilas, Diane. 2004. "Feta Unbound: Greek Cheese Triumphs in Court." New York Times, March 6: F5.

Levi-Strauss, Claude. 1962. Totemism. Translated by R. Needham. Harmondsworth: Penguin. 1969. The Raw and the Cooked. Translated by John and Doreen Weightman. New York: Harper and Row.

LoDico, Maria Francesca. 2008. "Reign of Terroir." Canadian Geographic 127: 47-49.

McGee, Robert, and Daniel Patterson. 2006. “Talk Dirt to Me." New York Times, May 6.

Moran, Emilio F. 2007. People and Nature: An Introduction to Human Ecological Relations. Malden: Blackwell Publishing.

SCruton, Roger. 2007a. "The Philosophy of Wine." In Questions of Taste: The Philosophy of Wine, edited by Barry C. Smith, pp. 1-20. New York: Oxford University Press.

-. 2007b. "In Defense of Terroir." The American Spectator, May: 42-44.

Payne, Alexander, And Jim Taylor. 2004. Sideways: The Shooting Script. New York: Newmarket Press.

TrubeK, Amy B. 2005. "Place Matters." In The Taste Culture Reader, edited by Carolyn Korsmeyer, pp. 260-271. New York: Berg.

Van Leeuwen, Cornelis, and Gerard SEguin. 2005. "The Concept of Terroir in Viticulture." Journal of Wine Research 17 (1): 1-10.

Whalen, Philip. 2005. "AA Merciless Source of Happy Memories': Gaston Roupnel and the Folklore of Burgundian Terroir." Journal of Folk:lore Research 44 (1): 21-40. 